\title{
Statyba
}

\section{ОЦЕНКА ПРОЧНОСТО И ДЕФОРМАТИВНОСТИ ЦЕНТРИФУГИРОВАННОГО БЕТОНА}

\author{
P. Вадлуа , Р. Клюкас , Р. Гаралявичюс , R. Vadlūga , R. Kliukas , R. \\ Garalevičius , R. Vadlūga , R. Kliukas \& R. Garalevičius
}

To cite this article: P. Вадлуа , Р. Клюкас , Р. Гаралявичюс , R. Vadlūga , R. Kliukas , R. Garalevičius , R. Vadlūga , R. Kliukas \& R. Garalevičius (1996) ОЦЕНКА ПРОЧНОСТО И ДЕФОРМАТИВНОСТИ ЦЕНТРИФУГИРОВАННОГО БЕТОНА, Statyba, 2:8, 73-83, DOІ: 10.1080/13921525.1996.10590175

To link to this article: https://doi.org/10.1080/13921525.1996.10590175

$$
\text { 曲 Published online: } 01 \text { Nov } 2012 .
$$

Submit your article to this journal 중

LIII Article views: 139 


\title{
ОЦЕНКА ПРОЧНОСТИ И ДЕФОРМАТИВНОСТИ ЦЕНТРИФУГИРОВАННОГО БETOHA
}

\author{
Р.Вадлуга, Р.Клюкас, Р.Гаралявичюс
}

\section{1. Введене}

Общеизвестно, что прочность бетона в реальных конструкциях может значительно отличаться от прочности бетона контрольных образцов. Это бывает из-за целого ряда факторов.

В Вильнюсском техническом университете (бывшем инженерно-строительном институте) с 1959 года проводятся исследования центрифугированного бетона, железобетона и конструкщий из него. За этот период накоплено много данных о механических характеристиках центрифугированного бетона. В данной работе более детально остановимся на новых исследованиях прочности и деформативности такого бетона для железобетонных элементов на разных стадиях их эксплуатации.

Процесс разрушения бетона при сжатии носит сложный характер и зависит от многих факторов. Он начинается с образования и развития микротрещин и заканчивается преодолением сопротивления бетона отрыву в плоскостях, расположенных параллельно направлению сжимающей силы. При этом трещины отрыва появляются в заполнителях либо между ними или же во всех компонентах бетона.

Истинную прочность центрифугированного бетона на сжатие характеризует его кольцевая прочность. На практике из-за сложности изготовления и испытания трубчатых образцов кольцевого сечения эту величину сравнительно трудно определить даже для контрольных образцов, не говоря уже о реальных железобетонных конструкциях.

\section{2. Особенности центрифугированного бетона}

Прочность и деформативность бетона находятся в прямой зависимости от водоцементного отношения. При центрифугировании состав бетона значительно изменяется. Из бетонной смеси отжимается $20 . .40 \%$ воды в зависимости от уплотняющей силы центрифугирования. Кроме того, как отмечает проф. А.Кудзис [1], после центрифугирования остаток воды сливается вместе с некоторыми добавками цемента и частицами легковесных загрязнений смеси. В бетоне, уплотненном любым другим способом, загрязнения остаются, уменьшая его прочность. Из-за этих и других факторов прочность центрифугированного бетона больше по сравнению с прочностью вибрированного бетона того же исходного состава. При центрифугировании прочность бетона может увеличиться до двух и более раз.

Структура и текстура вибрированного и центрифугированного бетонов получается разной. Для центрифугированного бетона свойственна неоднородная структура и текстура по толщине стенки трубчатого элемента. При центрифугировании более тяжелые составляющие бетонной смеси концентрируются у наружной поверхности элемента, где бетон получается более прочным и менее деформативным.

\section{3. Влияние армнрования}

\section{1. Общие сведения}

В железобетонных конструкциях благодаря сцеплению бетон работает совместно с арматурой. Наличие арматуры отражается на поведении бетона на всем протяжении эксплуатации конструкщии. 
В последние годы в железобетонных конструкциях широко применяется термически упрочненная арматура классов АT-IV, Ат-V. В сжатых элементах, армированных продольной высокопрочной стержневой арматурой классов А$\mathrm{V}$, Ат-V и выше, при наличии достаточного поперечного армирования в стальных стержнях пластические деформации не возникают почти до момента раздробления бетона, что способствует деформированию бетона на нисходящем участке его рабочей диаграммы $\sigma_{b}-\varepsilon_{b}$ (рис. 1).

a)

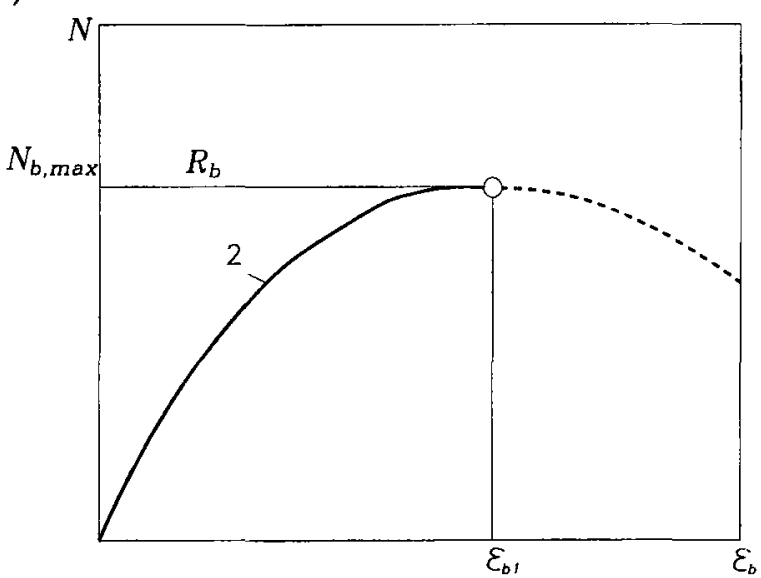

б)

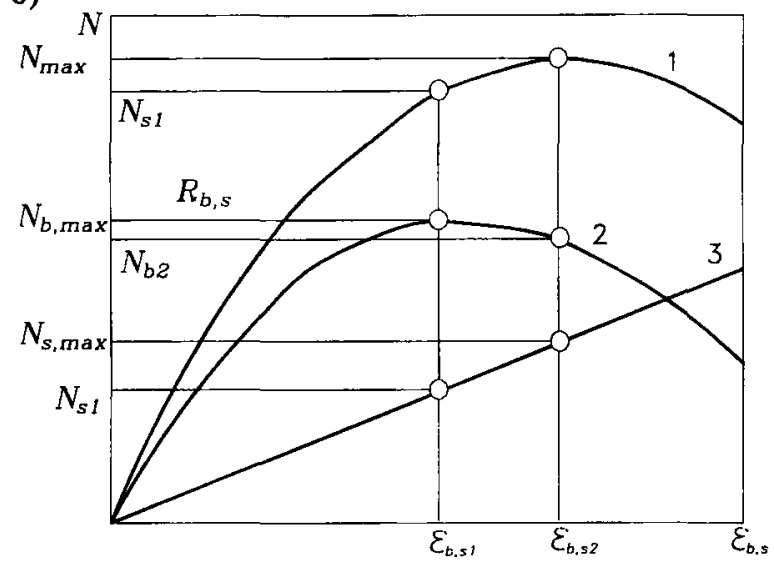

Рис. 1. Зависимость между продольными усилиями, воспринимаемыми железобетонным элементом (1), его бетоном (2) и продольной высокопрочной арматурой

(3), и продольными деформациями бетона при кратковременном осевом сжатии бетонного (a) и железобетонного (б) элемента

Fig. 1. Relatioship between longitudinal forces taken by reinforced concrete member (1), its concrete (2) and longitudinal high-strength reinforcement (3), and between longitudinal deformation due short- time axial compression of concrete (a) and reinforced concrete (b) member
При центрифугировании продольная и поперечная арматура оказывает некоторое отрицательное влияние на условия уплотнения и твердения бетонной смеси. Это сказывается на структуре и физико-механических характеристиках бетона. Из-за стесненных арматурой усадочных деформаций твердеющего бетона в нем возникают напряжения растяжения. В реальных несущих конструкциях они способствуют образованию и развитию микротрещин в бетоне, что отрицательно влияет на его прочность и начальный модуль деформаций.

С другой стороны, продольное и поперечное армирование способствует перераспределению усилий между стальной арматурой и бетоном, улучшая работу последнего на нисходящем участке рабочей диаграммы сжатия $\sigma_{b}-\varepsilon_{b}$. При этом уменышение шага поперечной арматуры (спирали) ведет к более выраженному объемному напряженному состоянию внутренней части стенки и этим как бы увеличивает сопротивление бетона внутренней части стенки центрифугированного элемента. Кроме того, благодаря сцеплению продольная арматура способствует более равномерному распределению напряжений по толщине стенки кольцевого сечения элементов и несколько повышает однородность деформаций сжатого бетона.

В лаборатории строительных конструкщий Вильнюсского технического университета проводились исследования по изучению влияния продольного и поперечного армирования на основные механические свойства центрифугированного бетона кольцевой прочности $R_{b}=30 \ldots 60$ МПа при кратковременном осевом сжатии [2-6].

Образцы, внешний диаметр которых 260 или 500 мм, высота $400 \ldots 800$ мм и толшина стенки $35 . .80 \mathrm{MM}$, изготовлялись методом однослойного центрифугирования. В качестве продольной арматуры применялась высокопрочная стержневая арматура класса Ат-V диаметром 10, 12 и 14 мм. Спиральная арматура была из проволоки класса Вр-I диаметром 4 и 5 мм. Коэффициент продольного армирования $\mu_{s}$ 
варьировался от 1,5 до $6 \%$, а коэффициент поперечного армирования $\mu_{c i r}$ - от 0,2 до $1,2 \%$, чему соответствовал шаг спирали от 40 до 100 MM.

\section{2. Влияние продольного армирования}

Исследования показали, что рост процента продольного армирования при увеличении количества продольных арматурных стержней значительно (до 20\%) снижает кольцевую прочность $R_{b, s}$ и начальный модуль $E_{b, s}$ деформаций бетона [2]. Это снижение может быть оценено по формулам:

$$
\begin{gathered}
\alpha_{s, 1}=R_{b, s} / R_{b}=1-\beta \mu_{s}, \\
\alpha_{s, 2}=E_{b, s} / E_{b}=1-6(\gamma-0,4) \mu_{s},
\end{gathered}
$$

где $\beta=0 \ldots 3$ и $\gamma \geq 0,4$ - коэффициенты, зависяшие от прочности бетона и крупности заполнителей (гранитного щебня) [2].

\section{3. Влиянпе поперечного армировяния}

Опытами А.Квядараса [5] и нашими [6] установлено, что на механические свойства центрифугированного бетона, кроме продольного, оказывает влияние и поперечное армирование.

Это влияние аналогично влиянию, оказываемому на бетон ядра, заключенного внутри обоймы колонн с косвенным армированием. Выявлено, что уменьшение шага спирали (при проценте поперечного армирования $\mu_{c i r}=0,25$ ...1,25\%) приводит к увеличению конструкционной прочности бетона (предела сопротивления бетона сжатия) до 20\% [6] (см. табл. 1). Такое сравнительно незначительное влияние спирали на конструкционную прочность центрифугированного бетона можно объяснить тем, что напряженно деформированное состояние трубчатого образца более близко к плоскому, чем к объемному. Известно [5], что для бетона двухосевое плоское сжатие практически не влияет на его прочность. Она близка к его призменной (кольцевой) прочности.
В работе [6] предложено влияние спирального армирования ( $\left.\mu_{c i r}=0,25 \ldots 1,25 \%\right)$ на кольцевую прочность и начальный модуль деформаций центрифугированного бетона оценивать по формулам:

$$
\begin{aligned}
\alpha_{c i r, 1}=R_{b, c i r s} / R_{b} & =0,81+0,9 \mu_{c i r}-0,6 \mu_{c i r}^{2},(3) \\
\alpha_{c i r, 2} & =E_{b, s} / E_{b} \approx 1
\end{aligned}
$$

Таким образом, опытами установлено, что интенсивность спирального армирования практически не оказывает влияния на начальный модуль деформаций центрифугированного бетона. Это объясняется тем, что в начальной стадии нагружения (в которой определяется начальный модуль деформаций), т. е. при сравнительно малых напряжениях, армирование не оказывает заметного влияния на физико-механические характеристики бетона, не имеющего микротрещин.

\section{4. Совместное влияние продольного и поперечного армирования}

Из вышеизложенного следует, что влияние поперечной и продольной арматуры на сопротивление и начальный модуль деформаций центрифугированного бетона за счет изменения условий изготовления, твердения и возникновения эффекта обоймы для железобетонных элементов кольцевого сечения может быть как положительным, так и отрицательным.

В работе [4] предлагалось совместное влияние продольного и поперечного армирования на прочность и начальный модуль деформаций центрифугированного бетона оценивать по формулам:

$$
\begin{aligned}
& \alpha_{1}=R_{b, s} / R_{b}=1-\omega\left(\mu_{s}-(0,1-s) / 2\right) \leq 1,(5) \\
& \alpha_{2}=E_{b, s} / E_{b}=0,78-s-\mu_{s}+0,002 R_{b} \leq 1 .(6)
\end{aligned}
$$

Здесь $\omega=1 \ldots 2,5-$ коэффициент, величина которого зависит от прочности бетона $R_{b}$ и коэффициента продольного армирования $\mu_{s} ; s$ - шаг спирали в м. 
1 таблида. Соотношения механических характеристик армированного только спиралью и неармированного центрифугированного бетона

Table 1. Ratios of mechanical characteristics of spun concrete with spiral reinforcement only and with no reinforcement

\begin{tabular}{|c|c|c|c|c|c|c|c|c|}
\hline \multicolumn{3}{|c|}{ Характеристика образцов } & \multirow{3}{*}{$\begin{array}{l}\text { Коли- } \\
\text { чество } \\
\text { образ- } \\
\text { цов }\end{array}$} & $\begin{array}{l}\text { Кольцевая } \\
\text { прочность }\end{array}$ & \multicolumn{4}{|c|}{ Соотношения } \\
\hline \multirow{2}{*}{$\begin{array}{c}\text { коэффициент } \\
\text { поперечного } \\
\text { армирования } \\
\left(\mu_{c i r}\right)_{m}\end{array}$} & \multirow{2}{*}{$\begin{array}{c}\text { шаг } \\
\text { спирали } \\
\\
S\end{array}$} & \multirow{2}{*}{$\begin{array}{c}\text { диаметр } \\
\text { спиральной } \\
\text { проволоки } \\
d_{c i r}\end{array}$} & & \multirow{2}{*}{$\begin{array}{c}\begin{array}{c}\text { Модуль } \\
\text { деформаций }\end{array} \\
\frac{\left(R_{b}\right)_{m}}{\left(E_{b}\right)_{m} \times 10^{-4}}\end{array}$} & \multicolumn{2}{|c|}{ прочности } & \multicolumn{2}{|c|}{$\begin{array}{r}\text { модуля } \\
\text { деформаций }\end{array}$} \\
\hline & & & & & $\left(\frac{R_{b, c i r}}{\left(R_{b}\right)_{m}}\right)_{m}$ & $\begin{array}{l}\text { коэффи- } \\
\text { циент } \\
\text { вариации }\end{array}$ & $\left(\frac{E_{b, c i r}}{\left(E_{b}\right)_{m}}\right)_{m}$ & $\begin{array}{l}\text { коэффи- } \\
\text { циент } \\
\text { вариации }\end{array}$ \\
\hline$\%$ & MM & MM & & МПа & & $\%$ & & $\%$ \\
\hline 0,44 & 100 & & 3 & & 1,073 & 1,2 & 0,988 & 1,8 \\
\hline 0,63 & 70 & 5 & 3 & $\underline{30,2}$ & 1,169 & 0,8 & 0,976 & 1,3 \\
\hline 1,09 & 40 & & 3 & 2,563 & 1,091 & 0,5 & 0,958 & 0,6 \\
\hline 0,28 & 100 & & 3 & & 1,028 & 2,9 & 0,995 & 1,5 \\
\hline 0,43 & 70 & 4 & 5 & $\underline{50,0}$ & 1,070 & 1,8 & 1,009 & 1,5 \\
\hline 0,75 & 40 & & 4 & 3,085 & 1,130 & 1,6 & 0,988 & 1,7 \\
\hline 0,44 & 100 & & 3 & & 1,086 & 2,9 & 1,014 & 2,8 \\
\hline 0,64 & 70 & 5 & 5 & $\underline{50,0}$ & 1,164 & 1,5 & 1,004 & 2,8 \\
\hline 1,17 & 40 & & 6 & 3,114 & 1,060 & 2,5 & 0,980 & 1,2 \\
\hline
\end{tabular}

В наших исследованиях для трубчатых образцов из бетона кольцевой прочности $R_{b}=30 \ldots 60 \mathrm{MПа,} \mathrm{армированных} \mathrm{продольной}$ $\left(\mu_{s}=1 \ldots 6 \%\right)$ и поперечной арматурой $\left(\mu_{c i r}=\right.$ $=0,25 \ldots 1,25 \%)$ при шаге спирали $s=0,04 \ldots 0,1$ м это влияние проявлялось в следующем (см. табл. 2):

- уменьшение шага спирали увеличивает сопротивление сжатию бетона $R_{b, s}$ только до $10 \%$;

- увеличение процента продольного армирования $\mu_{s}$ приводит к снижению коэффициента $\alpha_{1}$ по (5), оценивающего влияние армирования на прочность бетона, до $10 \%$;

- уменышение шага спирали (в наших опытах от 100 до 40 мм) снижает опытный коэффициент $\alpha_{2}$ по (6), оценивающий влияние армирования на начальный модуль деформаций бетона, лишь до 5\%. При этом диаметр проволоки спирали практически не влияет на начальный модуль деформаций армированного бетона $E_{b, s}$;

- увеличение процента продольного армирования с 1,5 до $5,6 \%$, чему соответствует увеличение числа продольных арматурных стержней с 6 до 12 , уменьшает начальный модуль деформаций армированного бетона $E_{b, s}$ на $8 . .10 \%$ (см. табл. 2);

- коэффициент $\alpha_{2}$ по (6), оцениваюший влияние армирования на начальный модуль деформаций центрифугированного бетона, зависит также от его прочности (см. табл. 2).

Следует отметить, что текстурные изменения бетона, вызываемые наличием продольной и поперечной арматуры, более значительно снижают начальный модуль деформаций, нежели прочность бетона трубчатого сжатого образца. Это снижение достигает соответственно 20 и $10 \%$.

Проведенные экспериментальные исследования показали, что в стадии, близкой $\mathrm{K}$ разрушению сжатого центрифугированного элемента, бетон работает на нисходящем участке диаграммы $\sigma_{b}-\varepsilon_{b}$. При этом деформации армированного бетона $\varepsilon_{b s, 1}$, соответствующие кольцевой прочности $R_{b, s}$, превышают аналогичные величины $\varepsilon_{b 1}$ неармированного бетона. 
2 таблица. Соотношение механических характеристик армированного и неармированного центрифугированного бетона

Table 2. Ratios of mechanical characteristics of reinforced and non-reinforced spun concrete

\begin{tabular}{|c|c|c|c|c|c|c|c|c|}
\hline \multicolumn{3}{|c|}{ Характеристика образцов } & \multirow{3}{*}{$\begin{array}{c}\text { Коли- } \\
\text { чество } \\
\text { образцов }\end{array}$} & \multirow{3}{*}{$\begin{array}{c}\begin{array}{c}\text { Кольцевая } \\
\text { прочность }\end{array} \\
\begin{array}{c}\text { Модуль } \\
\text { деформаций }\end{array} \\
\frac{\left(R_{b}\right)_{m}}{\left(E_{b}\right)_{m} \times 10^{-4}}\end{array}$} & \multicolumn{4}{|c|}{ Соотношения } \\
\hline \multirow{2}{*}{$\begin{array}{l}\text { коэффи- } \\
\text { циент } \\
\text { продоль- } \\
\text { ного } \\
\text { армиро- } \\
\text { вания } \\
\left(\mu_{\text {cir }}\right)_{m}\end{array}$} & \multirow{2}{*}{$\begin{array}{c}\text { шаг } \\
\text { спирали } \\
\\
s\end{array}$} & \multirow{2}{*}{$\begin{array}{c}\text { диаметр } \\
\text { спиральной } \\
\text { проволоки } \\
\\
d_{c i r}\end{array}$} & & & \multicolumn{2}{|c|}{ прочности } & \multicolumn{2}{|c|}{$\begin{array}{r}\text { модуля } \\
\text { деформаций }\end{array}$} \\
\hline & & & & & $\left(\frac{R_{b, s}}{\left(R_{b}\right)_{m}}\right)_{m}$ & $\begin{array}{l}\text { коэффи- } \\
\text { циент } \\
\text { вариации }\end{array}$ & $\left(\frac{E_{b, c i r}}{\left(E_{b}\right)_{m}}\right)_{m}$ & $\begin{array}{c}\text { коэффи- } \\
\text { циент } \\
\text { вариации }\end{array}$ \\
\hline$\%$ & MM & MM & & МПа & & $\%$ & & $\%$ \\
\hline 1,56 & $\begin{array}{r}100 \\
70 \\
40 \\
\end{array}$ & 5 & $\begin{array}{l}3 \\
3 \\
3 \\
\end{array}$ & $\begin{array}{r}37,2 \\
3,310 \\
\end{array}$ & $\begin{array}{l}0,964 \\
0,973 \\
1,018 \\
\end{array}$ & $\begin{array}{l}2,8 \\
2,1 \\
2,0 \\
\end{array}$ & $\begin{array}{l}0,953 \\
0,913 \\
0,910 \\
\end{array}$ & $\begin{array}{l}3,9 \\
2,9 \\
2,3 \\
\end{array}$ \\
\hline 1,56 & $\begin{array}{r}100 \\
70 \\
40\end{array}$ & 5 & $\begin{array}{l}3 \\
3 \\
3\end{array}$ & $\begin{array}{r}59.8 \\
4,080\end{array}$ & $\begin{array}{l}0,979 \\
0,998 \\
1,012\end{array}$ & $\begin{array}{l}1,4 \\
2,6 \\
2,4 \\
\end{array}$ & $\begin{array}{l}0,990 \\
0,970 \\
0,951 \\
\end{array}$ & $\begin{array}{l}0,5 \\
2,4 \\
2,7 \\
\end{array}$ \\
\hline 3,11 & $\begin{array}{r}100 \\
70 \\
40 \\
\end{array}$ & 4 & $\begin{array}{l}4 \\
4 \\
4 \\
\end{array}$ & $\begin{array}{r}38,1 \\
3,045 \\
\end{array}$ & $\begin{array}{l}0,956 \\
0,968 \\
0,994 \\
\end{array}$ & $\begin{array}{l}2,1 \\
2,6 \\
2,4 \\
\end{array}$ & $\begin{array}{l}0,900 \\
0,882 \\
0,855 \\
\end{array}$ & $\begin{array}{l}3,0 \\
2,9 \\
4,1 \\
\end{array}$ \\
\hline 3,03 & $\begin{array}{r}100 \\
70 \\
40\end{array}$ & 4 & $\begin{array}{l}6 \\
8 \\
6 \\
\end{array}$ & $\begin{array}{r}48,3 \\
3,279 \\
\end{array}$ & $\begin{array}{l}0,976 \\
0,970 \\
1,015 \\
\end{array}$ & $\begin{array}{l}4,3 \\
4,1 \\
3,8 \\
\end{array}$ & $\begin{array}{l}0,950 \\
0,913 \\
0,901 \\
\end{array}$ & $\begin{array}{l}4,2 \\
3,8 \\
3,4 \\
\end{array}$ \\
\hline 3,10 & $\begin{array}{r}100 \\
70 \\
40\end{array}$ & 5 & $\begin{array}{l}3 \\
3 \\
3 \\
\end{array}$ & $\begin{array}{r}33,8 \\
2,750\end{array}$ & $\begin{array}{l}0,923 \\
0,938 \\
0,953\end{array}$ & $\begin{array}{l}2,4 \\
2,6 \\
2,3 \\
\end{array}$ & $\begin{array}{l}0,858 \\
0,830 \\
0,812 \\
\end{array}$ & $\begin{array}{l}3,2 \\
2,8 \\
2,5 \\
\end{array}$ \\
\hline 3,18 & $\begin{array}{r}100 \\
70 \\
40 \\
\end{array}$ & 5 & $\begin{array}{l}5 \\
5 \\
5 \\
\end{array}$ & $\begin{array}{r}\frac{40.9}{2,927} \\
\end{array}$ & $\begin{array}{l}0,923 \\
0,963 \\
0,985 \\
\end{array}$ & $\begin{array}{l}3,6 \\
2,8 \\
3,2 \\
\end{array}$ & $\begin{array}{l}0,889 \\
0,880 \\
0,846 \\
\end{array}$ & $\begin{array}{l}3,2 \\
2,9 \\
3,0 \\
\end{array}$ \\
\hline 3,01 & $\begin{array}{l}100 \\
70 \\
40 \\
\end{array}$ & 5 & $\begin{array}{l}5 \\
7 \\
5 \\
\end{array}$ & $\begin{array}{r}\underline{50,2} \\
3,171 \\
\end{array}$ & $\begin{array}{l}0,978 \\
0,987 \\
0,983 \\
\end{array}$ & $\begin{array}{l}3,0 \\
4,2 \\
2,8 \\
\end{array}$ & $\begin{array}{l}0,929 \\
0,926 \\
0,906 \\
\end{array}$ & $\begin{array}{l}3,1 \\
2,8 \\
3,2 \\
\end{array}$ \\
\hline 5,67 & $\begin{array}{l}100 \\
70 \\
40 \\
\end{array}$ & 5 & $\begin{array}{l}3 \\
3 \\
3 \\
\end{array}$ & $\begin{array}{r}\underline{31,6} \\
2,910 \\
\end{array}$ & $\begin{array}{l}0,881 \\
0,909 \\
0,941 \\
\end{array}$ & $\begin{array}{l}1,4 \\
1,8 \\
2,6 \\
\end{array}$ & $\begin{array}{l}0,846 \\
0,834 \\
0,799 \\
\end{array}$ & $\begin{array}{l}2,3 \\
2,1 \\
2,8 \\
\end{array}$ \\
\hline 5,39 & $\begin{array}{c}100 \\
70 \\
40 \\
\end{array}$ & 5 & $\begin{array}{l}3 \\
3 \\
3 \\
\end{array}$ & $\begin{array}{r}\underline{41,3} \\
3,490 \\
\end{array}$ & $\begin{array}{l}0,909 \\
0,935 \\
0,960 \\
\end{array}$ & $\begin{array}{l}2,4 \\
2,1 \\
2,2 \\
\end{array}$ & $\begin{array}{l}0,881 \\
0,847 \\
0,843 \\
\end{array}$ & $\begin{array}{l}2,0 \\
2,4 \\
2,8 \\
\end{array}$ \\
\hline 5,61 & $\begin{array}{c}100 \\
70 \\
40\end{array}$ & 5 & $\begin{array}{l}3 \\
3 \\
3\end{array}$ & $\frac{51,0}{3,540}$ & $\begin{array}{l}0,932 \\
0,953 \\
0,972\end{array}$ & $\begin{array}{l}2,9 \\
3,6 \\
3,1\end{array}$ & $\begin{array}{l}0,915 \\
0,897 \\
0,880\end{array}$ & $\begin{array}{l}2,4 \\
1,8 \\
3,0\end{array}$ \\
\hline
\end{tabular}


3 таблиц. Показатели сжимаемости центрифугированного бетона при осевом сжатии

Table 3. Compressibility characteristics of spun concrete in axial compression

\begin{tabular}{|c|c|c|c|c|c|c|c|}
\hline $\begin{array}{l}\text { Коэффициент } \\
\text { продольного }\end{array}$ & & Диаметр & Количество & Средняя & деформация & $\begin{array}{r}\text { Коэфо } \\
\text { вар }\end{array}$ & $\begin{array}{l}\text { (иенты } \\
\text { ции }\end{array}$ \\
\hline $\begin{array}{c}\mu_{s} \\
\%\end{array}$ & $\begin{array}{c}s \\
\mathrm{~mm}\end{array}$ & $\begin{array}{l}d_{\text {cir }} \\
\mathrm{mm}\end{array}$ & $n$ & $\left(\varepsilon_{b, s 1}\right)_{m} \times 10^{3}$ & $\left(\varepsilon_{b, s 2}\right)_{m} \times 10^{3}$ & $\mathrm{v}\left(\varepsilon_{\mathrm{b}, \mathrm{s} 1}\right)$ & $\mathrm{v}\left(\varepsilon_{\mathrm{b}, \mathrm{s} 2}\right)$ \\
\hline 0 & - & - & 86 & 2.17 & - & 12.56 & - \\
\hline 1,56 & \multirow{4}{*}{40} & 5 & 6 & 2,61 & 2,91 & 2,35 & 3,46 \\
\hline 3,07 & & 4 & 10 & 2,73 & 3,39 & 4,22 & 6,22 \\
\hline 3,10 & & 5 & 13 & 2,86 & 3,71 & 5,98 & 12,15 \\
\hline 5,56 & & 5 & 9 & 2,89 & 4,15 & 6,53 & 7,95 \\
\hline 1,56 & \multirow{4}{*}{70} & 5 & 6 & 2,45 & 2,65 & 1,88 & 4,50 \\
\hline 3,10 & & 4 & 12 & 2,70 & 3,18 & 4,10 & 5,95 \\
\hline 5,56 & & 5 & 15 & 2,64 & 3,16 & 3,82 & 9,43 \\
\hline 1,56 & & 5 & 9 & 2,66 & 3,61 & 2,95 & 10,67 \\
\hline 1,56 & \multirow{4}{*}{100} & 5 & 6 & 2,21 & 2,34 & 4,71 & 3,47 \\
\hline 3,07 & & 4 & 10 & 2,33 & 2,65 & 6,65 & 7,61 \\
\hline 3,10 & & 5 & 13 & 2,38 & 2,78 & 6,53 & 10,86 \\
\hline 5,56 & & 5 & 9 & 2,44 & 3,16 & 4,57 & 11,30 \\
\hline
\end{tabular}

Средние значения и коэффициенты вариации статистического распределения предельной деформации исследованного нами сжатого центрифугированного бетона приведены в табл. 3. Из данных таблицы видно, что продольные деформации $\varepsilon_{b, s 1}$ и $\varepsilon_{b, s 2}$ бетона повышаются с увеличением коэффициента продольного армирования $\mu_{s}$, уменьшением шага спирали $s$ и прочности бетона $R_{b}$. При этом коэффициент вариации $v\left(\varepsilon_{b, s 2}\right)$ данной деформации, как и следовало ожидать, для бетонных элементов получается большим, чем для армированных образцов.

Согласно проведенному корреляционнорегрессионному анализу, опытная деформация

$$
\varepsilon_{b, s 1}=\gamma_{\varepsilon} \varepsilon_{b 1},
$$

где $\varepsilon_{b 1}$ - продольная деформация $\left(-2,2410^{-3}\right)$, $\gamma_{\varepsilon}$ - коэффициент, учитываюший влияние армирования и прочности бетона на его деформативность, определяемый по формуле

$$
\gamma_{\varepsilon}=(1,3-3 s)\left(1+\mu_{s}\right)\left(1,15-0,0025 R_{b, s}\right) \geq 1 .
$$

\section{4. Изменене механических харақтеристик с течением времени}

Общеизвестно, что с течением времени прочность и деформативность бетона меняются. Это изменение связано со многими факторами. Одним из них является вид и уровень напряженно-деформированного состояния. Многие исследователи заметили, что длительное сжатие усилиями, не вызывающими микроразрушения (образования микротрещин) бетона, способствует повышению его прочности и начального модуля деформаций.

В 1980-1984 годах в лаборатории строительных конструкщий ВТУ проводились экспериментальные исследования этого явления с элементами из центрифугированного бетона [7]. Исследовались элементы, армированные напрягаемой и ненапрягаемой арматурой. Предварительные напряжения бетона элементов составили $\sigma_{b, p}=(0,15 \ldots 0,45) R_{b, s}$ и были как ниже, тақ и несколько выше нижней границы микротрешинообразования $R_{T, 0}$. 
Спустя 100 суток прочность и начальный модуль деформаций обжатого центрифугированного бетона увеличились соответственно на $10 \ldots 15 \%$ и $10 . .20 \%$ по сравнению с необжатым.

Увеличение прочности и начального модуля деформаций центрифугированного бетона вследствие длительного обжатия объясняется многими причинами, из которых следует выделить [7]:

- дополнительную гидратацию геля из-за отжатия "свободной воды",

- уплотнение структуры бетона из-за выжимания геля в поры и в микротрещины цементного камня, что приводит к самозалечиванию последних.

При расчете конструкщий по несущей способности и по деформациям это обстоятельство предлагается учитывать путем умножения нормативных значений призменной прочности $R_{b}$ и модуля деформаций бетона $E_{b}$ соответственно на коэффициенты [7]:

$$
\begin{aligned}
\beta_{1}= & R_{b, s}\left(\tau_{l}\right) / R_{b}\left(\tau_{0}\right)=0,265 \eta_{0}+1,1, \\
\beta_{2} & =E_{b, s}\left(\tau_{1}\right) / E_{b}\left(\tau_{0}\right)= \\
& =1+1,69 \eta_{0}-6,04 \eta_{0}^{2}+7,75 \eta_{0}^{3},
\end{aligned}
$$

где $\eta_{0}$ - начальная интенсивность длительного сжатия бетона. В этих опытах она колебалась в пределах $0,15 \ldots 0,45$.

Для практических расчетов предложено с обеспеченностью $\geq 95 \%$ принять коэффициенты $\beta_{1}=\beta_{2}=1,15$ [7].

Важным фактором, оказывающим влияние на прочность центрифугированного бетона, является возраст бетона. А.М.Невиль [8] утверждает, что в возрасте больше одного года бетон благодаря гидратации прежде негидратированного цемента и, возможно, также в результате карбонизации еще набирает прочность.

В 1970 году подвергались испытанию бетонные образцы кольцевого сечения с внешним диаметром 260 мм, толщиной стенки $30 . .40$ мм и высотой 260 мм, изготовленные методом однослойного центрифугирования на роликовой центрифуге [9]. Бетонная смесь приготовлялась на портландцементе. При изготовлении образцы подвергались тепловлажностной обработке в течение одних суток.

Прочность на сжатие и растяжение пропаренного центрифугированного бетона определялась в возрасте 14, 120, 240 и 360 суток прямым сжатием и растяжением образцов кольцевого сечения. Результаты исследований приведены в табл. 4.

Часть образцов кольцевого сечения была испытана спустя 26 лет (9600 суток) хранения в нормально-влажностных условиях. Испытания проводились на осевое сжатие и раскалывание. Ввиду того, что после длительного хранения образцов было мало, испытанию на сжатие и раскалывание подвергались не целые центрифугированные образцы кольцевого сечения, а их части в виде призм. По результатам испытаний на раскалывание ориентировочно можно судить о прочности бетона на растяжение $[10,11]$. Результаты экспериментальных исследований приведены частично в табл. 4 и подробнее в табл. 5 и 6.

4 таблнца. Рост прочности на сжатие и растяжение центрифугированного бетона

Table 4. Increase in compression and tension strength of spun concrete

\begin{tabular}{|c|c|c|c|c|c|c|c|c|}
\hline $\begin{array}{c}\text { Возраст } \\
\text { образцов } \\
\text { в сутках }\end{array}$ & $\begin{array}{c}\text { Прочность } \\
\text { на сжатие, } \\
\text { МПа }\end{array}$ & $\begin{array}{c}\text { Коэффи- } \\
\text { циент } \\
\text { вариции, } \\
\%\end{array}$ & $\begin{array}{c}\text { Количество } \\
\text { образцов, } \\
\%\end{array}$ & $\begin{array}{c}\text { Прирост } \\
\text { прочности, } \\
\%\end{array}$ & $\begin{array}{c}\text { Прочность на } \\
\text { растяжение, } \\
\text { МПа }\end{array}$ & $\begin{array}{c}\text { Коэффи- } \\
\text { циент } \\
\text { вариаций, } \\
\%\end{array}$ & $\begin{array}{c}\text { Количе- } \\
\text { ство } \\
\text { образцов }\end{array}$ & $\begin{array}{c}\text { Прирост } \\
\text { прочности, }\end{array}$ \\
\hline 14 & 39 & 10,6 & 36 & - & 1,92 & 9,2 & 18 & - \\
\hline 120 & 44 & 8,3 & 36 & 11,8 & 2,27 & 11,3 & 18 & 18,2 \\
\hline 240 & 47 & 9,1 & 18 & 20,3 & 2,53 & 9,6 & 9 & 31,8 \\
\hline 360 & 51 & 8,2 & 18 & 30,8 & 2,60 & 10,8 & 9 & 35,4 \\
\hline 9600 & $69 * *$ & 13,4 & & 77,4 & $3,08^{*}$ & 9,6 & & $60,4^{*}$ \\
\hline
\end{tabular}

* Величина получена с использованием формулы (12)

** По результатам испытания колец и призм (см. табл. 6) 
Ввиду того, что образцов было мало и они были сравнительно коротки, не было возможности провести прямое испытание на растяжение. Для сравнительной оценки влияния возраста бетона на его прочность при растяжении воспользовались результатами испытаний такого бетона на раскалывание. Согласно стандарту [11] предел прочности бетона на осевое растяжение рекомендуется вычислять по формулам при испытании на раскалывание:

цилиндров

$$
R_{b, t}=\frac{2}{\pi} \frac{F}{A}=0,637 \frac{F}{A},
$$

кубов

$$
R_{b, t}=0,5187 \frac{F}{A}
$$

5 таблша. Результаты испытания на раскалывание центрифугированных бетонньх образцов

Table 5. Results of splitting tests on spun concrete

\begin{tabular}{|c|c|c|}
\hline $\begin{array}{c}\text { Разрушаюшая } \\
\text { сила } \\
F\end{array}$ & $\begin{array}{c}\text { Размеры сечения } \\
\text { раскалывания } \\
h \times d\end{array}$ & $\begin{array}{c}\text { Напряжения } \\
\text { раскалывания } \\
R\end{array}$ \\
\hline $\mathbf{k N}$ & $\mathrm{cm}$ & $\mathrm{M \Pi a}$ \\
\hline 100,0 & $26 \times 6,6$ & 5,83 \\
\hline 45,0 & $26 \times 3,3$ & 5,24 \\
\hline 50,2 & $26 \times 3,3$ & 5,83 \\
\hline 19,2 & $8,7 \times 3,3$ & 6,69 \\
\hline 18,0 & $8,3 \times 3,3$ & 6,57 \\
\hline 18,9 & $8,1 \times 3,3$ & 7,07 \\
\hline 120,0 & $26 \times 8,0$ & 5,77 \\
\hline 60,0 & $26 \times 4,0$ & 5,77 \\
\hline 58,0 & $26 \times 4,0$ & 5,58 \\
\hline 18,3 & $8,3 \times 4,0$ & 5,51 \\
\hline 18,8 & $7,9 \times 4,0$ & 5,93 \\
\hline 19,8 & $8,9 \times 4,0$ & 5,55 \\
\hline 110,0 & $26 \times 7,2$ & 5,88 \\
\hline 50,0 & $26 \times 3,6$ & 5,34 \\
\hline 58,0 & $26 \times 3,6$ & 6,20 \\
\hline 22,9 & $8,4 \times 3,8$ & 7,17 \\
\hline 17,2 & $8,3 \times 3,7$ & 5,59 \\
\hline 16,8 & $8,2 \times 3,8$ & 5,38 \\
\hline \multicolumn{2}{|c|}{ Среднее значение $(R)_{m}$, МПа } & 5,94 \\
\hline \multicolumn{2}{|c|}{ Коэффициент вариации v, \% } & 9,56 \\
\hline \multicolumn{2}{|c|}{$\begin{array}{l}\text { Среднее квадратическое } \\
\text { отклонение } \sigma, \mathrm{MПа}\end{array}$} & 0,568 \\
\hline
\end{tabular}
samples
В этих формулах $F$ - разрушающая сила при скалывании, $A$ - площадь сечения раскалывания.

Теоретически прочность бетона осевому растяжению можно определить по эмпирической формуле Фере (Ferret):

$$
R_{b, t}=0,233 \sqrt[3]{R^{2}}
$$

где $R$ - прочность на сжатие бетона.

В табл. 7 приведены опытные и расчетные величины предела прочности центрифугированного бетона при осевом сжатии и растяжении. В технической литературе содержатся сведения о том, что прочность, определяемая путем раскалывания кубов или цилиндров, зависит от ряда факторов (диаметра применяемых

6 таблщща. Результаты испытания на осевое сжатие центрифугированных бетонньг образцов (призм)

\begin{tabular}{|c|c|c|c|}
\hline $\begin{array}{c}\text { Pазруша- } \\
\text { ющая } \\
\text { сила } \\
F \\
F\end{array}$ & $\begin{array}{c}\text { Площадь } \\
\text { поперечного } \\
\text { сечения } \\
A\end{array}$ & $\begin{array}{c}\text { Высота } \\
\text { образца } \\
h \\
h\end{array}$ & $\begin{array}{c}\text { Кольцевая } \\
\text { прочность } \\
\text { бетона } \\
R_{b}\end{array}$ \\
\hline $\mathrm{MN}$ & & $\mathrm{cm}^{2}$ & МПа \\
\hline 1,649 & $239,0^{*}$ & 26 & $69,0^{*}$ \\
\hline 0,425 & 59,4 & 26 & 71,5 \\
\hline 0,415 & 54,4 & 26 & 76,5 \\
\hline 0,483 & 56,1 & 26 & 86,1 \\
\hline 0,195 & 28,3 & 8,7 & 68,9 \\
\hline 0,225 & 31,6 & 8,4 & 71,2 \\
\hline 0,211 & 30,3 & 8,3 & 69,6 \\
\hline 0,370 & 68 & 26 & 54,4 \\
\hline 0,350 & 64 & 26 & 54,7 \\
\hline 0,330 & 56 & 26 & 58,9 \\
\hline 0,261 & 36,8 & 7,9 & 70,9 \\
\hline 0,304 & 38,4 & 7,9 & 79,1 \\
\hline 0,480 & 70,3 & 26 & 68,3 \\
\hline 0,410 & 60,8 & 26 & 66,9 \\
\hline 0,265 & 32,3 & 8,35 & 81,6 \\
\hline 0,199 & 32,6 & 8,4 & 61,0 \\
\hline \multicolumn{3}{|c|}{ Среднее значение $\left(R_{b}\right)_{m}$, МПа } & 69,2 \\
\hline \multicolumn{3}{|c|}{ Коэффициент вариации v, \% } & 13,4 \\
\hline \multicolumn{3}{|c|}{$\begin{array}{l}\text { Среднее квадратическое } \\
\text { отклонение б, МПа }\end{array}$} & 9,287 \\
\hline
\end{tabular}

Table 6. Results of axial compression test on spun concrete samples (prisms)

* Результаты испытания целого кольца 
для раскалывания стальных стержней, масштабного фактора, скорости нагружения и т. д.). Вследствие неоднородности структуры бетона формула (13) не всегда дает достоверные величины $R_{b, t}$. Из табл. 7 видно, что величины $R_{b, t}$, полученные прямым испытанием образцов в возрасте до одного года, значительно отличаются от расчетных величин, полученных по формуле (13). По результатам прямых испытаний прочности на сжатие и растяжение центрифугированного бетона в возрасте до одного года (см. табл. 4) формула Фере для этого бетона может быть представлена несколько измененной:

$$
R_{b, t}=0,1833 \sqrt[3]{R_{b}^{2}}
$$

Аппроксимируя формулу (14) для того же бетона в возрасте 26 лет, получаем величину $R_{b, t}=3,09 \mathrm{MПа,} \mathrm{что} \mathrm{практически} \mathrm{совпадает} \mathrm{с}$ опытным значением $R_{b, t}$, полученным с использованием формулы (12) (табл. 4 и 7).

Результаты пусть немногочисленных и частично косвенных испытаний показали, что с течением времени центрифугированный бетон набирает прочность как на сжатие, так и на растяжение. Установлено, что в течение года прочность бетона увеличилась примерно на $30 \%$, а спустя 26 лет - более чем на $60 \%$.

Тенденция нарастания прочности на сжатие центрифугированного бетона с течением времени замечена и в другой нашей работе [12]. В этих опытах возраст центрифугированного

бетона достигал 1,5 года.

\section{6. Выводы}

1. Продольное и поперечное армирование центрифугированных элементов кольцевого сечения несколько ухудшает условия уплотнения и твердения бетона. Вследствие этого начальный модуль и кольцевая прочность бетона армированных элементов несколько снижаются по сравнению с неармированными. Однако увеличение интенсивности поперечного армирования несколько увеличивает сопротивление сжатию бетона, заключенного внутри спирали. Это частично компенсирует потери прочности бетона.

2. Длительное осевое обжатие, не вызывающее значительных микроразрушений, оказывает положительное влияние на начальный модуль деформаций и прочность центрифугированного бетона, что следует учитывать в расчетах конструкций по несущей способности и деформациям.

3. Нарастание прочности как на сжатие, так и на растяжение центрифугированного бетона происходит в течение довольно продолжительного времени. Это явление может объясняться дтительной гидратацией цементного камня. На это обстоятельство следует обращать внимание при оценке несущей способности и длительной безопасности конструкщий в зависимости от условий эксплуатации.

7 таблна. Сопоставление опьтных и расчетных величин прочности центрифугированного бетона при растяжении Table 7. Ratios of observed and calculated tension strength values of spun concrete

\begin{tabular}{|c|c|c|c|c|c|c|}
\hline \multirow[t]{3}{*}{$\begin{array}{l}\text { Возраст } \\
\text { образцов в } \\
\text { сутках }\end{array}$} & \multicolumn{2}{|c|}{ Опытные величины } & \multicolumn{2}{|c|}{$\begin{array}{c}\text { Расчетные значения } \\
\text { прочности на растяжение } \\
\left(R_{b, t}\right)_{c a l} \text { по формулам }\end{array}$} & \multicolumn{2}{|c|}{$\begin{array}{c}\text { Соотношения } \\
\left(R_{b, t}\right)_{\substack{\text { obs } \\
\text { формулам }}}\left(R_{b, t}\right)_{c a l} \text { по }\end{array}$} \\
\hline & $\begin{array}{c}\text { на сжатие } \\
\left(R_{b}\right)_{o b s}\end{array}$ & $\begin{array}{c}\text { на растяжение } \\
\left(R_{b, t}\right)_{o b s}\end{array}$ & $(13)$ & $(14)$ & $(13)$ & $(14)$ \\
\hline & $\mathrm{M \Pi а}$ & $\mathrm{M \Pi а}$ & $\mathrm{M \Pi a}$ & МПа & & \\
\hline 14 & 39 & 1,92 & 2,67 & 2,11 & 0,72 & 0,91 \\
\hline 120 & 44 & 2,27 & 2,90 & 2,27 & 0,78 & 1,00 \\
\hline 240 & 47 & 2,53 & 3,04 & 2,38 & 0,83 & 1,06 \\
\hline 360 & 51 & 2,60 & 3,20 & 2,52 & 0,81 & 1,03 \\
\hline 9600 & 69 & $3,08^{*}$ & 3,92 & 3,09 & 0,79 & 1,00 \\
\hline
\end{tabular}

* Величина получена с использованием формулы (12) 


\section{Литература}

1. А.П. Кудзис. Железобетонные конструкции кольцевого сечения. Вильнюс: Минтис, 1975. 225 с.

2. Г.А. Аксомитас, А.П. Кудзис. Оценка прочности центрифугированного бетона в сжатых элементах // Науч. тр. вузов Литовской ССР. Железобетонные конструкции, № 14. Оценка прочности железобетона. Вильнюс, 1985, с. 83-96.

3. Р.М. Клюкас, А.П. Кудзис. Влияние спиральной арматуры на деформативность центрифугированного бетона в сжатьх железобетонных элементах // Науч. тр. вузов Литовской ССР. Железобетонные конструкции, № 16. Деформативность бетона и железобетона. Витьнюс, 1989, с. 111-120.

4. Р.М. Клюкас. Влияние спирального армирования на прочность центрифугированных элементов с высокопрочной продольной арматурой при осевом и внецентренном сжатии // Вильнюсский ИСИ. Вильнюс, 1988. 21 с. Деп. в ЛитНИИТИ 13.06.1988, № 2123-Ли.

5. А.Б. Квядарас. Исследование работы элементов из центрифугированного бетона со спиральной арматурой при кратковременном и длительном нагружении // Тр. Вильнюсского ИСИ. Железобетонные конструкции, № 2. Вильнюс: Минтис, 1969 , c. $85-93$.

6. A. Kudzys, R. Kliukas, R. Vadlūga. Utilization of highstrength spun consrete and reinforcing steel in compressive structures // Utilization of high strength consrete. Symposium in Lillehammer, Norway, June 2023, Volume 1. 1993, p. 259-268.

7. А.П. Кудзис, В.И. Глебов. О прочности бетона в преднапряженных элементах колыевого сечения // Науч. тр. вузов Литовской ССР. Железобетонные конструкции, № 12. Повышение долговечности и прочности конструкций. Вильнюс, 1983, с. 93-99.

8. А.М. Невиль. Свойства бетона. Москва, 1972. 344 с.

9. А.П.А. Гаралявичюс. Исследование по полимерцементному центрифугированному бетону: Автореф. дис. ... канд. техн. наук. Каунас, 1970. 20 с.

10. A. Kudzys. O pevnosti odstredovaneho betonu v tahul // Stavebnicky Časopis, Bratislava, 1964, No 8, c. 493-500.

11. ГОСТ 4800-59. Бетон гидротехнический. Методы испытания бетона. Москва, 1959. 25 с.

12. Р.Р. Вадлуга. Исследование работы трубчатых образцов из центрифугированного высокопрочного бетона при центральном и внецентренном сжатии // Исследование по железобетонным конструкциям. Том II. Вильнюс, 1966, с. 81-88.

Iteikta 19961105

\section{CENTRIFUGUOTOJO BETONO STIPRUMO IR DEFORMATYVUMO VERTINIMAS}

\section{R. Vadlūga, R. Kliukas, R. Garalevičius}

\section{Santra u a}

Nagrinèjama keleto veiksnių: išilginès stipriosios armatūros, skersinès (spiralinès) armatūros, išankstinio apgniuždymo bei betono amžiaus ittaka centrifuguotojo betono mechaninèms savybèms.

Eksperimentais nustatyta, kad išilgine ir skersinè (spiralinè) armatūra blogina centrifuguotojo betono tankinimo ir kietejimo sąlygas. Tačiau spiralinè armatūra mažina gniuždomų centrifuguotụ žiedinio skerspjūvio elementy skersines deformacijas ir taip padidina betono stiprumą.

Eksperimenty metu centriniam gniuždymui buvo bandomi centrifuguoti žiedinio skerspjūvio elementai, kurių išorinis diametras lygus 260 ir $500 \mathrm{~mm}$, aukštis 400 arba 800 $\mathrm{mm}$, sienelès storis $35 \ldots 80 \mathrm{~mm}$. Bandiniai buvo armuoti išilginiais $10,12,14 \mathrm{~mm}$ skersmens strypais ir 4 ar $5 \mathrm{~mm}$ skersmens spirale. Išilginio armavimo koeficientas $\mu_{s}$ keitèsi nuo 1,5 iki $6 \%$, skersinio $\mu_{c i r}$ - nuo 0,25 iki $1,25 \%$, spiralès žingsnis $s$ kito nuo $40 \mathrm{iki} 100 \mathrm{~mm}$.

Bandant žiedus, ju betono stiprumas gniuždant $R_{b}$ buvo $30 \ldots 60 \mathrm{MPa}$. Minètų eksperimentu rezultatai pateikti 1,2 ir 3 lentelèse. Armavimo itaka tokio betono mechaninėms savybèms realiu konstrukciju elementuose siūloma vertinti (5) ir (6) formulèmis.

Straipsnyje aptariamos centrifuguotojo betono stiprio ir pradinio deformaciju modulio priklausomybès (9) ir (10) nuo išankstinio apgniuždymo intensyvumo.

Pateikiami naujausi eksperimentiniai duomenys apie betono gniuždomojo ir tempiamojo stiprio priklausomybę nuo jo amžiaus. Nustatyta, kad cementinio akmens hidratacija vyksta pakankamai ilgą laiką ir centrifuguotojo betono gniuždomasis ir tempiamasis stipris dideja.

Šj stiprio prieaugi iliustruoja 4 lentelèje pateikti eksperimenty rezultatai. Centrifuguotojo betono stipris 14, 120,240 ir 360 paru amžiuje buvo nustatytas tiesiogiai gniuždant ir tempiant žiedus (4 lentelè). Po 9600 parų (26 metu) dél riboto bandinilu (betoniniu žiedu) kiekio gniuždomasis betono stiprumas buvo nustatytas bandant ne žiedus, $o$ iš ju iškirptas prizmes. Tempiamasis stiprumas buvo nustatytas netiesioginiu būdu - kerpant minetas prizmes, kaip rekomenduoja standartas [11] pagal formulę (12). Šiu bandymų rezultatai pateikti 5 ir 6 lentelèse.

Teorinis ryšys tarp tempiamojo ir gniuždomojo betono stiprumo gali būti aprašytas Fere (Ferret) formule (13), kurią centrifuguotojo betono atveju mes siūlome šiek tiek pakoreguotą, t.y. (14).

Lyginamieji skaičiavimai parodè, kad pagal (14) formulę nustatytas centrifuguotojo betono skaičiuojamasis stipris atitinka tiesioginių bandymų rezultatus ( 7 lentelè).

\section{STRENGTH AND DEFORMABILITY ESTIMATION OF CENTRIFUGED CONCRETE}

\section{R. Vadlūga, R. Kliukas, R. Garalevičius}

S u m m a r y

Influence of several factors, namely high strength longitudinal reinforcement, transverse (spiral) reinforcement, precompression level and concrete age, on mechanical properties of centrifuged concrete is investigated.

It has been established by tests that longitudinal and transverse (spiral) reinforcement make worse compaction, casting and hardening conditions of centrifuged concrete. But the spiral reinforcement reduces transverse deformations of compressed centrifuged members of ring cross-section and hence increases concrete strength. During the experiments for central compression, centrifuged concrete members of a ring cross-section were investigated. 
The parameters of these members: diameter 260 and 500 $\mathrm{mm}$, height 400 and $800 \mathrm{~mm}$, web thickness $35 . .80 \mathrm{~mm}$. The specimens were reinforced by longitudinal bars of 10 , $12,14 \mathrm{~mm}$ diameter and 4 or $5 \mathrm{~mm}$ cross-section spirals. Coefficient of longitudinal reinforcement $\mu_{s}$ varied from 1,5 to $6 \%$, coefficient of transverse reinforcement $\mu_{c i r}$ from 0,25 to $1,25 \%$, lead of spirals - from 40 to $100 \mathrm{~mm}$.

During testing the ring concrete compressive strength $R_{b}$ was $30 . . .60 \mathrm{MPa}$. The results of the above-mentioned experiments are presented in Tables 1,2 and 3 . It is recommended to evaluate the reinforcement influence on mechanical properties of such concrete in members of real constructions by formulas (5) and (6).

Relationships of concrete strength, initial modulus of deformation and intensity of precompression (9) and (10) are discussed in this article.

The latest test results on relationship between concrete compression, tension strength and concrete age are presented. It is established, that hydration of cement takes quite a long time and compression and tension strength of centrifuged concrete increases.

This increase in strength is given in Table 4 . The strength of centrifuged concrete of $14,120,240$ and 360 days was determined by direct compression and tension of concrete rings (Table 4). After 9,600 days (26 years) due to a limited number of specimens (concrete rings) the compressive strength was determined by testing prisms cut from the rings. The tensile strength was determined indirectly - by cutting these prisms, as it is recommended by a standard [11] according to formula (12). The results of these tests are presented in Tables 5 and 6.

Theoretical connection between tensile and compressive strength may be described by Ferret formula (13), which we propose to use in a slightly changed form, i. e. as (14).

Comparative calculations showed that the centrifuged concrete strength calculated according formula (14) corresponds to the results of direct testing (Table 7).
Romualdas VADLūGa. Doctor, Associate Professor. Dept of Reinforced Concrete Structures. Vilnius Gediminas Technical University, 11 Saulètekio Ave, 2040 Vilnius.

A graduate of Kaunas Politechnical Institute (1962). Doctor's degree in 1967 (building structures). Since 1962 assistant, senior assistant, associated professor at the Dept of Building Structures, Dept of Reinforced Concrete Structures. Co-author of 2 textbooks. Lithuanian state prize for technical achievements. Author of more than 70 publications (research and design of reinforced concrete members of circular section). Research interests: mechanics of reinforced concrete structures and estimation of their reliability.

Romualdas KLIUKAS. Doctor, Associate Professor. Dept of Strength of Materials. Vilnius Gediminas Technical University, 11 Sauletekio Ave, 2040 Vilnius.

Doctor's degree in 1989 (building structures) at Vilnius Civil Engineering Institute. Researcher at the Dept of Reinforced Concrete Structures. Since 1989 senior assistant at the Dept of Strength of Materials. In 1990-1991 research visit to Buildings Scientific-Technical Research Centre in France. More than 20 consultancy works (assessment of serviceability of various structures, renovation projects of buildings). Research interests: structures in civil engineering, renovation of buildings, reinforced concrete theory, research and design of reinforced concrete structures applying high-strength concrete and high-yield reinforcement.

Adolfas Ričardas GARALEVIČIUS. Doctor, senior assistant. Dept of Building Technology and Management. Vilnius Gediminas Technical University, 11 Sauletekio Ave, 2040 Vilnius.

Doctor's degree in 1970 (building materials and structures) at Kaunas Politechnical Institute. Author of 90 publications. Research interests: building materials, concrete technology, reinforced concrete structures. 